\title{
LA TORRE DEL CASTILLO: \\ GÉNESIS DE UNA ANOREXIA RESTRICTIVA
}

\author{
THE TOWER OF THE CASTLE: \\ A CASE OF RESTRICTIVE ANOREXIA
}

\author{
María Martín Santacreu \\ ORCID: https://orcid.org/0000-0001-7122-3082 \\ Psicóloga general sanitaria en práctica privada. Barcelona, España
}

Cómo referenciar este artículo/How to reference this article:

Martín Santacreu, M. (2021). La torre del castillo: Génesis de una anorexia restrictiva. Revista de Psicoterapia, 32(119), 271-279. https://doi.org/10.33898/rdp.v29i109.226

\section{Resumen}

En este artículo se plantea la comprensión de las condiciones evolutivas, subyacentes a la aparición de la anorexia de tipo restrictivo durante la adolescencia, en base a la Teoría del Desarrollo Moral (Villegas 2011), a propósito del caso de una paciente que acude a terapia ya en la edad adulta. La consulta terapéutica viene motivada por la propuesta de fecundación asistida para facilitar un embarazo, lo que suscita dilemas especificos de su problemática anoréxica.

Palabras clave: anorexia, autonomía, familia, adolescencia, maternidad, fecundación asistida.

\begin{abstract}
This article proposes the understanding of the evolutionary conditions underlying the appearance of restrictive anorexia during adolescence, based on the Theory of Moral Development(Villegas 2011), regarding the case of a patient who attends therapy already in adulthood. The therapeutic consultation is motivated by the proposal of assisted fertilization to facilitate a pregnancy, which raises specific dilemmas to her anorexic problem.

Keywords: anorexia, autonomy, family, adolescence, motherhood, assisted fertilization.
\end{abstract}


Según la última versión del Manual Diagnóstico y Estadístico de los trastornos mentales (5 ed.; DSM-5; American Psychiatric Association, 2014) la anorexia nerviosa debe cumplir tres criterios diagnósticos principales:

a) Restricción de la ingesta energética en relación con las necesidades, que conduce a un peso corporal significativamente bajo con relación a la edad, el sexo, el curso del desarrollo y la salud física.

b) Miedo intenso a ganar peso o a engordar, o comportamiento persistente que interfiere en el aumento de peso, incluso con un peso significativamente bajo.

c) Alteración en la forma que uno mismo percibe su propio peso o constitución, influencia impropia del peso o la constitución corporal en la autoevaluación, o falta persistente de reconocimiento de la gravedad del bajo peso corporal actual.

En este artículo se pretende analizar las causas subyacentes a la emergencia de la anorexia de tipo restrictivo basándonos en la Teoría del Desarrollo Moral propuesta por Villegas (2011, 2013, 2018, 2020), más allá de los criterios descriptivos del caso diagnosticado en la adolescencia, que se corresponden con los criterios diagnósticos de anorexia nerviosa anteriormente citados.

\section{Contextualización del Caso y Demanda}

Berta (30 años) llega a la consulta con una demanda centrada en su futuro proyecto de maternidad. En el contacto telefónico inicial expresa que necesita terapia psicológica perinatal para "poder controlar los efectos que el proceso de in-vitro pueda tener en mi estado de ánimo y en mi cuerpo, ya que pasé por una anorexia en la adolescencia que me ha dejado secuelas".

Como observamos, aparecen durante el primer contacto elementos que tienen que ver tanto con el control de su "psique" como con el control de su cuerpo que la paciente relaciona directamente con la anorexia diagnosticada a los 14 años. A partir de esta sesión, pasamos a explorar su historia de vida en un proceso de psicoterapia.

\section{Historia de Vida y Contexto Familiar}

En la exploración inicial de su historia de vida, nos habla de una familia de origen con unos padres "muy padres", centrados en la educación y desarrollo de sus dos hijas (ella y su hermana, 5 años mayor).

Tanto la familia materna como la paterna tienen orígenes humildes, con antecedentes de emigración a fin de mejorar su calidad de vida. La familia paterna tiene su origen en un pueblo de Galicia y emigra a Catalunya en busca de trabajo. El padre de Berta, a pesar de no tener estudios, lleva adelante exitosamente una tienda de alimentos que finalmente acaba siendo una cadena comercial, que sigue funcionando en la actualidad. Su dedicación al trabajo implicaba no estar mucho tiempo en casa, siendo la madre, en el día a día, quien se ocupaba de la crianza de las niñas. De su padre destaca el haber sido exigente con él mismo a nivel laboral, 
inteligente, muy trabajador. Como figura paterna, Berta subraya la exigencia de su padre con los estudios, el énfasis en el esfuerzo y progreso personal, así como su coherencia al poner consecuencias cuando ellas se comportaban mal, un padre que trabajó "para dárselo todo a sus hijas".

El origen de la familia materna está en Andalucía y fueron los abuelos quienes emigraron a Catalunya en busca de trabajo. Una vez casada, la madre de Berta se dedicó a la casa y a la crianza de sus hijas. Berta la describe como "una madre muy cuidadora que priorizaba que estuviéramos cómodas por encima de exigirnos". Añade que su madre era alguien muy preocupada por las formas en lo social: "comportarse bien, tener una buena imagen, ser reservada y no exponerse a ser objeto de comentarios por parte de los demás”. Otro aspecto que destacar es la importancia que da la madre a la unión de la familia, por encima de la propia individualidad, reprimiendo su propia opinión para no "crear conflictos familiares".

En la descripción de las familias de origen podemos observar una diferencia clara en el estilo relacional de cada familia (Minuchin, 2003). Mientras que en la familia paterna prevalece una tendencia que prioriza el desarrollo individual ante la cohesión o unión familiar, en la familia materna existe una tendencia aglutinada donde la información circula entre los diferentes miembros sin tener en cuenta las diferentes jerarquías.

En cuanto al ámbito laboral, la familia paterna ha progresado socialmente y la mayor parte de las últimas generaciones han llegado a la universidad, mientras que en la familia materna según palabras de Berta: "no se han desarrollado y no han mejorado profesionalmente”. Esto se traduce en que en la familia materna prevalece todavía en la tercera generación ocupar puestos laborales que no requieren estudios superiores. Berta se siente identificada con la familia paterna y los valores de progreso, exigencia, esfuerzo y libertad, mientras que en la familia materna se siente "la oveja negra".

Con su hermana, Berta expresa haber tenido una relación muy difícil. Ella esperaba su proximidad y estima, pero su hermana la rechazaba, ignoraba y menospreciaba continuamente durante toda su infancia. Explica que su hermana tuvo muchos celos al nacer ella y que esta situación se enquistó y su madre ha admitido que no supo cómo redirigirla. Como consecuencia Berta se sintió muy rechazada y dejada de lado por su hermana, a la vez que indefensa, ya que su madre no actuaba delante de sus desprecios y minimizaba la situación. Esto se ha traducido en sentimientos de rabia desde su infancia que no se sentía legitimada a expresar para "no perder las formas, como decía mi madre".

La familia, debido a su progreso económico, decidió llevarlas a un colegio “exigente y bastante elitista”. Berta se sintió diferente y con poca sintonía con sus compañeras. En cambio, cuando iba al pueblo del padre en verano explica que se sentía muy a gusto, entendida y libre con sus amigos y amigas de allí, ya que no había pretensiones, ni artificialidad. Recuerda que, al inicio del curso, después de vacaciones, se sentía "la oveja negra” al volver al colegio. 
En el relato de su historia aparecen unos constructos familiares (Dallos, 1996) opuestos entre ambas familias de origen que tienen una incidencia en el desarrollo individual de Berta. La exigencia, el esfuerzo y libertad en la familia paterna, frente a la corrección, el no dar de qué hablar y la unión familiar en la materna. A esto se suma la vivencia de sentirse "rechazada" dentro de la familia nuclear, así como "no adecuada" respecto a su grupo de iguales. Ambas situaciones generan sentimientos de soledad y rabia que Berta no puede canalizar por el mandato familiar materno de "no perder las formas".

\section{La Anorexia: Un Intento de Tener Voz Propia}

Al llegar a la preadolescencia, aun cuando existían estos sentimientos respecto al grupo de iguales, formaba parte del grupo de las populares en el colegio. A pesar de no sentirse identificada con las chicas, no quería dejar de formar parte de este grupo. Alrededor de los 14 años las chicas con las que iba comienzan a hablar de ponerse a dieta y adelgazar: "era un entorno donde la apariencia importaba mucho”. Explica que para ella no tenía ningún sentido hacer dieta, pero les seguía el juego para no sentirse desplazada, aunque nunca iniciaba ninguna dieta: "Una de ellas, la cabecilla, me decía: 'siempre lo dices y nunca haces nada, no sé para qué hablas', hasta que un día para que me dejaran en paz y vieran que yo sí que tenía voz, decidí que iba a ser la que más en serio se tomaría la dieta y llevé las cosas al límite. Mi forma de defenderme fue la anorexia”.

Berta explica cómo esta reclusión en su cuerpo fue una forma de expresar su malestar: "en casa siempre callando, siempre manteniendo las formas; en el colegio sintiéndome diferente, apartada, poco adecuada... No podía más. Me sentía perdida y frustrada. Me he sentido muy sola desde pequeña”. Así comenzó su reclusión en su torre, donde los demás ya no podían dañarla, pero donde estaba a la vez aislada del mundo. Aquí, tal y como apunta Villegas (2011), la anorexia aparece como una dificultad evolutiva en adquirir criterios interpersonales y el adoptar como mecanismo el recluirse en el cuerpo, haciendo de éste su fortaleza.

Berta en este punto de su vida comienza a restringir alimentos en las tres comidas que hacía en el colegio durante el día (desayuno, almuerzo, merienda). Comenzó a disminuir peso, perdió su menstruación y la alarma no saltó hasta que una compañera del colegio alerta a los profesores de lo que está sucediendo y estos se ponen en contacto con la familia. La familia la lleva al pediatra quien le da la opción de hacer una dieta adecuada a su edad dirigida por la familia o hacer seguimiento con la enfermera y una psicóloga. Berta expresa haber escogido ella misma la segunda opción, ya que no se veía capaz de seguir una pauta dietética.

A pesar de iniciar el tratamiento, el peso siguió disminuyendo hasta que el sufrimiento que ve en su madre al llevarla a urgencias hace que vuelva a comer. "En urgencias me plantearon que si no comía y volvía allí otra vez esto supondría un ingreso. Vi el sufrimiento de mi madre, se puso a llorar... Después me enteré de que estaba tomando antidepresivos y pensé que no podía hacerle esto. Aquí 
comencé a comer para no hacerla sufrir más”.

Normalización del Síntoma Alimentario

Berta comienza a comer, pero no sale de su torre, ya que el control sobre qué comería, cuándo y bajo qué circunstancias continúa. Así fue como comenzó a gestarse un funcionamiento basado en el control del cuerpo a través de la ingesta: "me autodeterminé a través del control. Comencé a hacerlo dentro de unos límites aceptables, pero que yo marcaba y no dejaba que nadie me dijera nada al respecto". La familia se adapta a que coma solo lo que ella quiera y ella misma se prepare la comida ya que nunca comía en presencia de otros (“no quería ver sus miradas”). El síntoma se instala como un funcionamiento normalizado en la familia y se instaura un tabú alrededor del tema de la comida que ya no vuelven a tocar.

Esta torre que Berta se construyó la protege de la relación con los demás: su familia y sobre todo con sus iguales. "Yo sentía una rabia que no sabía cómo expresar". Esta muralla en la vida diaria se traduce en una actitud defensiva hacia cualquier percepción de ataque de los demás, así como una reclusión en el control de su cuerpo (alimentación, sueño, peso, ....). Los demás son percibidos como una amenaza y como ella misma dice: "me debo defender poniendo límites claros, si no la gente se sobrepasa”. Berta expresa sentirse sola en su torre, tener la necesidad de poder expresar lo que le sucede, pero a la vez siente que los demás la decepcionan y que, por lo tanto, no puede bajar sus murallas.

\section{Frustración: Se Refuerzan las Murallas}

Ir a la universidad le permitió contactar con diferentes realidades, salir de la burbuja donde había estado durante su infancia y adolescencia, poder establecer relaciones con personas de un entorno diferente al suyo. Aun así se siente atrapada en una paradoja: "Entre los elitistas y pijos no encajaba durante mi adolescencia, pero entre la gente normal de la universidad era yo la pija y de nuevo era la señalada, la no apropiada". Esta percepción refuerza su actitud defensiva ante los "ataques de los demás” dado que no soporta ni siquiera la idea que se la pueda criticar. Esta inseguridad que siente en lo social durante la etapa de juventud refuerza el funcionamiento construido durante la adolescencia, fundamentado en la exigencia y el control. Como resultado Berta se focaliza en sus estudios y carrera profesional "para ser la mejor enfermera de quirófano que se pueda ser".

Recibe del exterior comentarios sobre ser una persona fría, distante, con mucho control emocional y muy fuerte, pero en cambio internamente ella se siente insegura e inestable emocionalmente. Cuando contacta con esta sensación de inseguridad y soledad se da cuenta de que recurre a incrementar las restricciones y el control del peso.

\section{Relación de Pareja}

En la actualidad lleva 8 años de relación y cuatro años casada. Explica que la relación con su marido (de profesión médico) fue algo diferente a lo que le había 
sucedido con anteriores parejas cuyo valor prioritario era el aspecto físico.

Cuando lo conoció y la relación se estabilizó, hubo una disminución del control alimentario. Habla de su marido como alguien que la valora y legitima su deseo en todo momento. Nunca juzgó sus “problemas de alimentación” y la animaba a que hiciera y comiera lo que le apeteciera en cada momento. Aun cuando a ella inicialmente no le satisfacía la relación al 100\% explica que su marido siempre ha recogido sus necesidades y esto ha permitido que la relación evolucionara.

El dilema actual relacionado con la maternidad se desencadena cuando hace tres años descubren una enfermedad degenerativa en el marido, la cual debe ser controlada exhaustivamente. Este descubrimiento puso en jaque a la pareja, ya que Berta tuvo dudas de si la relación sería viable por los cambios que supuso en sus rutinas y también en sus proyectos vitales.

\section{La Posible Maternidad Amenaza la Estabilidad de la Torre}

Dada la gravedad de la enfermedad, les informaron que podría afectar a sus planes de ma-paternidad. Esta situación llevó a Berta y a su marido a plantearse ser padres cuando este hecho vital no tenía una fecha fija en el calendario de la pareja y estaban centrados en poder disfrutar sus años de pareja sin hijos, viajando a destinos exóticos (esta es la mayor afición de Berta), a poder ser un par de veces al año. Se habían planteado ser padres en el futuro, pero esto no era un deseo inminente por parte de ninguno de los dos. Berta pasa el siguiente año "irritable, encerrada, deprimida, sin hablar con nadie” debido a la crisis interna que le supone este cambio de planes en su proyecto de vida. Se plantea dejar la relación, no tanto porque dude de la estima de su marido, si no por no sentirse capaz de tolerar que la vida haya decidido por ella.

Desde el servicio hospitalario que les atiende se les informa de diferentes opciones a considerar en el caso que quisieran intentar ser padres: seguir un proceso natural y hacer un estudio genético a las 12 semanas de embarazo para decidir en ese momento si interrumpirlo, o no, en función de si el embrión tiene el gen de la enfermedad; hacer un proceso in-vitro con células de ambos, donde se hace una selección previa de los embriones que implantarían, los cuales ya no tendrían el gen relacionado con la enfermedad de su marido; o hacer un proceso in-vitro con células de donantes. Para poder hacer este proceso en la sanidad pública no pueden escoger la fecha, ni el momento exacto en que realizarlo, ya que hay una lista de espera para poder acceder.

Después de un proceso largo de decisión, Berta apuesta por continuar el proyecto de pareja y deciden entrar en lista de espera para el proceso de in-vitro (optan por la segunda opción de in-vitro con células propias genéticamente seleccionadas).

Es importante señalar que, aunque Berta expresa "haber decidido seguir adelante con la relación y el proyecto de maternidad”, las circunstancias son interpretadas por parte de Berta como “impuestas” desde el exterior, que ella no decide. De este modo comienza a introducirse en el camino a la maternidad desde 
una “imposición, una obligación” donde siente que realmente no está decidiendo, aunque haya escogido una de las opciones posibles.

\section{El Conflicto Actual}

A partir de la elección de someterse a un proceso in-vitro, Berta comienza a ver amenazados diferentes ámbitos de su vida de forma anticipada. Se debate entre permanecer dentro de la torre o comenzar a desmontarla para dar cabida a los cambios que esta nueva etapa supone. Dado este dilema decide que antes de exponerse al proceso de in-vitro necesita "gestionar o normalizar su fobia por ser madre”, de ahí su demanda de terapia.

Al desglosar este objetivo ("gestionar o normalizar su fobia por ser madre"), Berta analiza cómo la maternidad podría afectar a diferentes áreas de su vida y expone los siguientes objetivos específicos a trabajar en terapia:

- Imagen corporal: "gestionar o normalizar el cambio físico y que esto no me acabe afectando en el embarazo ni en la crianza del niño/a”. Berta expresa miedo a que el proceso hormonal que deberá seguir altere su figura y se sienta "hinchada" y no pueda compensar con más ejercicio (realiza entrenamientos de "cross-fit" contraindicados con el proceso invitro a seguir) o no pueda restringir su dieta como viene haciendo desde la adolescencia.

- Estado de ánimo: que las hormonas la hagan sentirse descontrolada y no pueda mantener a raya a su ansiedad. "No ser yo ni emocionalmente, ni físicamente y que esto me haga perder el control de mi misma".

- Relaciones: "gestionar o normalizar la rabia y sensación de vacío que tengo respecto a mi entorno (familia y amigas) y respecto a mí, y que no me afecte a emprender la maternidad". Berta teme que los cambios hormonales no le permitan controlar la rabia interna que siente con los demás y llegue a tener problemas en el trabajo, con la familia o la pareja.

- Necesidades básicas de alimentación y sueño:

o que se altere su ritual debido a su "fobia a no dormir" que implica dormir siempre sola, tomar melatonina e infusiones, dormir bajo unas condiciones de temperatura, luz y ruido controladas.

o que el proceso de embarazo ponga en riesgo su "demasiado sana” alimentación que pasa por una restricción casi total de los carbohidratos y una ingesta de muy pocos alimentos.

- Carrera profesional: "gestionar como orientarme laboralmente en el proceso de maternidad”. Berta explica que su carrera profesional como enfermera ha sido una prioridad en su vida y no sabe cómo la maternidad cambiará su implicación con el oficio y diferentes investigaciones en las que participa. Debido a su "fobia a dormir" trabaja en el turno de tarde y no sabe si sería capaz de modificar su turno al de mañana, como han hecho la mayoría de sus compañeras en el momento de ser madres. 


\section{La Maternidad Amenaza la Torre}

Como hemos podido ver, Berta se recluye en la torre amurallada de su cuerpo, al no haber podido integrar las relaciones interpersonales en la adolescencia (Villegas, 2011) y como reacción a un contexto que siente invalidante y poco reconocedor. Véase Hernángomez (2020) para un análisis de las implicaciones del TCA en el desarrollo individual.

Hasta este momento ha podido permanecer dentro de su torre, aunque haya podido asumir responsabilidades adultas y desarrollarse profesionalmente. Sus cimientos están fundamentados en el control y la exigencia respecto a su cuerpo, sus rutinas y su trabajo, a través de los cuales ella se siente segura y resguardada de las amenazas del mundo exterior.

En este momento vital, la enfermedad de su marido y la maternidad la llevan a un dilema que no sabe cómo resolver y que pone en jaque su funcionamiento interno: ¿Cómo permanecer en la torre cuando la vida la pone cara a cara delante de elementos que ella no controla y que pueden cambiar sus planes vitales (enfermedad del marido)? ¿Cómo permanecer dentro de la torre si para ser madre el habitante de la torre debe cambiar su figura corporal, engordar, y esto amenaza con romper las murallas? ¿Cómo permanecer dentro de la torre si la maternidad supone priorizar inicialmente el cuidado del bebé y modificar sus estrictas rutinas (alimentación, sueño, ejercicio)? ¿Cómo permanecer dentro de la torre si el tener un hijo/a puede modificar su trabajo, tal y como ella lo ha planificado y sobre el cual ha construido su identidad?

Berta se enfrenta en este momento vital al reto del cambio de regulación interna que implicaría desmontar la torre que construyó en reacción al mundo social. Se siente incapaz de enfrentar la maternidad desde una vivencia más ilusionante o placentera porque precisamente este cambio implica modificar la propia estructura (Watzlawich et al., 1992), el propio funcionamiento interno de regulación.

El proceso de cambio implicaría un camino hacia la autonomía y para conseguirlo debería dejar de fundamentar su vida en el control, tanto del cuerpo como de su contexto. Crear otros cimientos vitales que no sean construidos como reacción al entorno, si no en base a las necesidades y deseos del habitante de la torre, es decir, de ella misma. Este es un elemento destacable en la emergencia de la anorexia restrictiva, la determinación de ella misma en contraposición a las relaciones sociales que le provocan un sufrimiento que no puede expresar.

Por lo tanto, está en juego que Berta salga de una posición reactiva para poder elaborar un diálogo entre ella y sus circunstancias vitales. La maternidad pone en jaque su funcionamiento interno y es, a la vez, una oportunidad para poder iniciar un desarrollo personal no reactivo al entorno, si no adaptativo a su crecimiento vital. La maternidad puede ser una oportunidad para comenzar a regularse desde otras estructuras diferentes al control, como podría ser conectar con el deseo de ser madre. Si Berta sale de esta posición reactiva y puede conectar, por ejemplo, con este deseo, las murallas de la torre ya no serían necesarias o sería ella misma 
quien vería que para evolucionar en el sentido que ella quiere, éstas deben derrumbarse. Al igual que una ciudad amurallada, como la Barcelona del siglo XIX, debió decidir en un momento de su historia derribar sus murallas para poder continuar creciendo, Berta tiene delante de sí, en este momento vital, un dilema que le hace replantear si puede crecer y expandirse, permaneciendo dentro de su torre con las murallas intactas.

Como dice Villegas (2011): “cuando se habla desde el punto de vista psicológico, la palabra autonomía significa esencialmente capacidad de autodeterminación, es decir, no sólo de actuar o de regirse por sí mismo como un autómata, sino de decidir según una voluntad intencional en base a la elección de objetivos prefigurados de los que uno es responsable". Por lo tanto, el reto evolutivo de Berta es, no solo aceptar que su cuerpo pueda cambiar en el proceso de maternidad, sino construirse a sí misma desde ella misma, no como reacción al exterior. Implica determinarse desde ella misma, no desde la frustración y la rabia que ha sentido y siente hacia los demás, sino en relación dialéctica con el mundo que le rodea.

\section{Referencias}

American Psychiatric Association (2014). Manual diagnóstico y estadístico de los trastornos mentales (5a ed.). Panamericana.

Dallos, R. (1996). Sistemas de creencias familiares. Paidós.

Hernangómez, L. (2020). Complejidad de los trastornos alimentarios [Editorial]. Revista de Psicoterapia, 31(115), 1-3. https://doi.org/10.33898/rdp.v31i115.351

Minuchin, S. (2003). Familias y terapia familiar. Gedisa.

Villegas, M. (2011). El error de Prometeo: Psico(pato)logía del desarrollo moral. Herder.

Villegas, M. (2013). Prometeo en el diván. Psicoterapia del desarrollo moral. Herder.

Villegas, M. (2018). La teoría del desarrollo moral en el marco del análisis existencial. Revista de Psicoterapia, 29(109), 1-38.

Villegas, M. (2020). Fenomenología clínica de los siete pecados capitales. Revista de Psicoterapia, 31(116), 147-168. https://doi.org/10.33898/rdp.v31i116.412

Watzlawich, P., Weakland, J. H. y Fisch, R. (1992). Cambio. Herder. 